\title{
COMEN CUP COMPETITION POINTS ANALYSIS OF ARIANA FIGURE IN ARTISTIC SWIMMING
}

\author{
Gökçe Akgün ${ }^{\mathrm{i}}$ \\ İstanbul University - Cerrahpaşa, \\ Institute of Graduate Studies, \\ Department of Movement and Training Sciences, \\ Turkey
}

\begin{abstract}
:
The aim of this study is to examine the athlete performance of Ariana, one of the obligatory figures in artistic swimming COMEN competitions, in terms of year and age. It is important to analyze the competition results of the athletes according to years, age groups, individual development and countries. For the figure performance points of the athletes, the official COMEN Mediterranean Artistic Swimming Cup competition results were checked. Within the scope of the research, the competitions held in 2014-2019 were examined. The performances of the same athletes competing in different years and the countries with regular participation are listed for evaluation. Ariana point averages of these countries were calculated according to general and years. One Way ANOVA and Wilcoxon Signed Ranks tests were used for statistical analysis. There was a significant difference between the groups when comparing the Ariana artistic swimming figure by years $(p<0.01)$. As a result of comparing the years with each other, it was found that there was a difference between 2017 and other years $(p<0.01)$. The results of the competition were compared by dividing them into 13, 14 and 15 age groups. There was a significant difference between these age groups $(\mathrm{p}<0.01)$. Ariana point averages and total mean and standard deviation values of 9 countries that participated continuously in 2014-2019 were determined. When the Ariana figure points of the same athletes were divided into 13-14, 14-15 and 13-15 age groups, it was understood that there were significant differences between the groups $(p<0.01)$. As the age of the athletes increases, the increase in Ariana figure points shows a significant difference. This situation is also present in the points of the same athletes in different age groups. The points of Bulgaria, France, Greece, Hungary, Italy, Russia, Spain, Switzerland and Turkey, which participated continuously in the years covering the research, are decisive for the competition ranking and the estimation of the Ariana figure points. The average point according to the year of the competition and the average point of the countries that regularly participate have been made suitable for planning for the development of athletes. With the study we prepared,
\end{abstract}

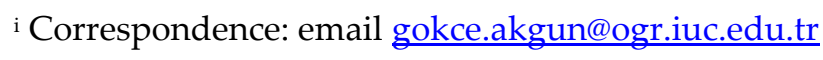


it was possible to make figure point plans in determining the performance development goals of artistic swimmers.

Keywords: artistic swimming, COMEN Cup, Ariana figure, FINA

\section{Introduction}

Artistic swimming is one of the water sports affiliated with FINA (Fédération Internationale de Natation) and LEN (The Ligue Européenne de Natation) (FINA, 2013; LEN, 2019; LEN, 2020). It is among the sports at the Summer Olympic Games. There are many competitions of artistic swimming in various age groups internationally. Competitions and general rules are determined by FINA (FINA, 2013; FINA, 2017). LEN organizes the European continental competitions. According to FINA and LEN rules, national team level competitions are held in three main groups: 13 - 15 years old, junior (16 - 18 years old), and senior (over 18 years old) (FINA,2013; FINA, 2017; LEN, 2020). Therefore, the youngest age group competitions in which national teams are represented are 13 - 15 years old. Most athletes perform in their countries and in special international competitions up to this age group (FINA, 2013; LEN, 2019; LEN, 2020).

There are COMEN (Confédération Méditerranéenne de Natation) Cup races in artistic swimming, which are attended by 13- 15 year old. COMEN artistic swimming cup competitions are held regularly in the LEN calendar every year (COMEN, 2008; COMEN, 2010; LEN 2020). Competitions are held in two stages. The first stage figure consists of second-stage musical choreography routines. COMEN Cup competitions are mainly held in accordance with FINA and LEN rules (COMEN, 2008; LEN 2020). Figure competitions are realized by performing two compulsory and two optional artistic swimming figures by all athletes one by one. Selective figures are announced before the start of the competition and, as a rule, each athlete makes the same elective figure. Musical choreography routines are applied in solo, duet, mixed duet, team, and free combination types. The results of the official competition are determined by the figure and the total point of musical routines (LEN, 2020; Ntomali et al., 2021).

Mandatory and elective figures in figure racing are updated every four years by the FINA artistic swimming technical committee. The figure of Ariana featured in both 2013-2017 and 2017-2021. Due to this feature, the importance of the Ariana figure in artistic swimming competitions was revealed by deciding to use it for eight years without interruption. Ariana's figure consists of 5 transitional movements in terms of its structural features. The movements in the figure were the basis of many artistic swimming movements, figures, and elements (FINA, 2013; FINA, 2017). The state of the Ariana figure in the artistic swimming rule book and its difficulty levels are shown in figure 1.1 (FINA, 2017). 


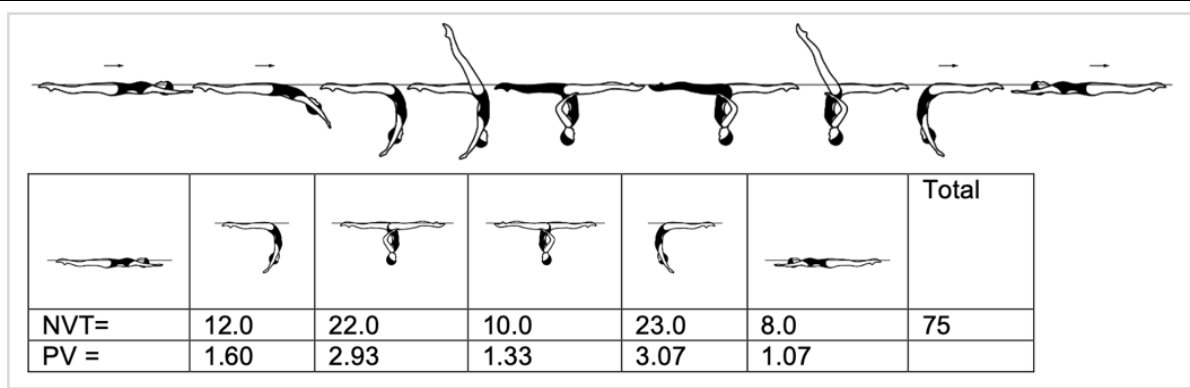

Figure 1.1: Ariana figure

The aim of this study is to examine the athlete performance of Ariana, one of the obligatory figures in artistic swimming COMEN competitions, in terms of year and age. It is important to analyze the competition results of the athletes according to years, age groups, individual development and countries. It is intended to emphasize the importance of competition points by determining the relationship of artistic swimming basic movements in the Ariana figure with the elements of junior and adults.

The scoring distribution of Ariana, who is a mandatory figure in 13-15 year old athletes, has been determined. During the two periods (2013-2107 and 2017-2021), the similarity and difference status of the points of the athletes from the Ariana figure used in the competitions according to age groups were examined. In this way, it was understood whether the age factor was one of the factors in getting high points. Our research will allow predicting the competition rankings by determining the Ariana figure points of the countries that participate regularly. In addition, it will be a resource for the determination of target points in terms of athlete development.

\section{Method}

2013-2017 and 2017-2021 FINA artistic swimming rule books were examined for detailed analysis of the artistic swimming figure examined within the scope of the research and to determine the movements contained in it. For the figure performance points of the athletes, the official COMEN Mediterranean Artistic Swimming Cup competition results were checked. The results of the competition are listed in accordance with the distribution of athletes and countries.

Within the scope of the research, competitions in 2014, 2015, 2016, 2017, 2018 and 2019 were examined. All athletes' points are listed by selecting the Ariana figure from the results of the official competition. Disqualified athletes were determined and eliminated, and the figure points of all other athletes were classified according to the years. The performances of the same athletes who competed in different years are listed for evaluation. In the years examined in the research, the countries that participated continuously were determined. Ariana point average values of these countries were calculated according to general and years. In terms of basic figure structure, the distribution of transitional movements including the Ariana figure in the elements of youth and adults has been determined. 
Ariana figure points of athletes competing in artistic swimming between 2014 and 2019 were compared. The point distributions of 13, 14 and 15 year old athletes were examined. One Way ANOVA test was applied for these two analyses. Wilcoxon Signed Ranks Test was applied to compare the Ariana figure points of the same athletes at different ages. Ariana's figure point averages were determined according to the years by determining the countries that participated for 6 years without interruption. SPSS 26.0 program was used for statistical analysis.

\section{Results}

Ariana figure performances of athletes aged 13-15 years in the artistic swimming COMEN Cup competitions were compared in terms of age group. First, figure points in 2014, 2015, 2016, 2017, 2018 and 2019 were analyzed. Ariana's figure points in the years of competition examined were compared with One Way ANOVA (Table 3.1). Accordingly, it was understood that there was a significant difference between the groups when comparing the Ariana artistic swimming figure by years $(p<0.01)$. As a result of comparing the years with each other, it was found that there was a difference between 2017 and other years $(p<0.01)$. Since the variances of the groups formed according to the years did not show an equal distribution Games-Howell one of the Post hoc tests, was used in the one-to-one comparison.

Table 3.1: Comparison of Ariana points by year

\begin{tabular}{|c|c|c|c|c|c|}
\hline Competition year & $\mathbf{n}$ & Mean \pm Standard d. & $\mathbf{F}$ & p & Significant difference \\
\hline 2014 & 208 & $15.54 \pm 1.39$ & \multirow{7}{*}{17.272} & \multirow{7}{*}{0.000} & \multirow{7}{*}{$\begin{array}{l}2014-2017(0.000) \\
2015-2017(0.000) \\
2016-2017(0.000) \\
2017-2018(0.000) \\
2017-2019(0.000)\end{array}$} \\
\hline 2015 & 241 & $15.32 \pm 1.31$ & & & \\
\hline 2016 & 185 & $15.44 \pm 1.30$ & & & \\
\hline 2017 & 256 & $14.53 \pm 1.27$ & & & \\
\hline 2018 & 236 & $15.40 \pm 1.54$ & & & \\
\hline 2019 & 163 & $15.37 \pm 1.52$ & & & \\
\hline Total & 1289 & $15.24 \pm 1.43$ & & & \\
\hline
\end{tabular}

*Results with a difference at $\mathrm{p}<0.003$ significance level according to Bonferroni correction.

Ariana's figure results in 2014, 2015, 2016, 2017 and 2018 were compared by splitting into 13, 14 and 15 age groups (Table 3.2). Since the birth dates of the athletes were not given clearly in the official results of 2019, they could not be used in the statistical analysis. As a result of the One-Way ANOVA test, it was understood that there was a significant difference between the groups $(\mathrm{p}<0.01)$. Since the variances of the groups formed according to age were equally distributed, Bonferroni, one of the Post hoc tests, was preferred for one-to-one comparison. 
COMEN CUP COMPETITION POINTS ANALYSIS OF ARIANA FIGURE IN ARTISTIC SWIMMING

Table 3.2: Comparison of Ariana points by 13, 14 and 15 age groups

\begin{tabular}{|l|c|c|c|c|c|}
\hline & $\mathbf{n}$ & Mean \pm Standard d. & F & $\mathbf{p}$ & Significant difference $^{*}$ \\
\cline { 1 - 3 } 13 & 158 & $14.48 \pm 1.37$ & & & $13-14(0.000)$ \\
\cline { 1 - 2 } 14 & 389 & $15.15 \pm 1.41$ & \multirow{3}{*}{0.000} & $14-15(0.002)$ \\
\cline { 1 - 2 } & 579 & $15.46 \pm 1.36$ & & & $13-15(0.000)$ \\
\hline Total & 1126 & $15.22 \pm 1.42$ & & \\
\hline
\end{tabular}

${ }^{*}$ Results with a difference at $\mathrm{p}<0.017$ significance level according to Bonferroni correction.

The average of the Ariana figure points of the athletes of Bulgaria, France, Greece, Hungary, Italy, Russia, Spain, Switzerland and Turkey, which regularly participated in the years examined within the scope of the research, was determined. For this first, the annual averages and then the 6-year general average was calculated (Figure 3.1).

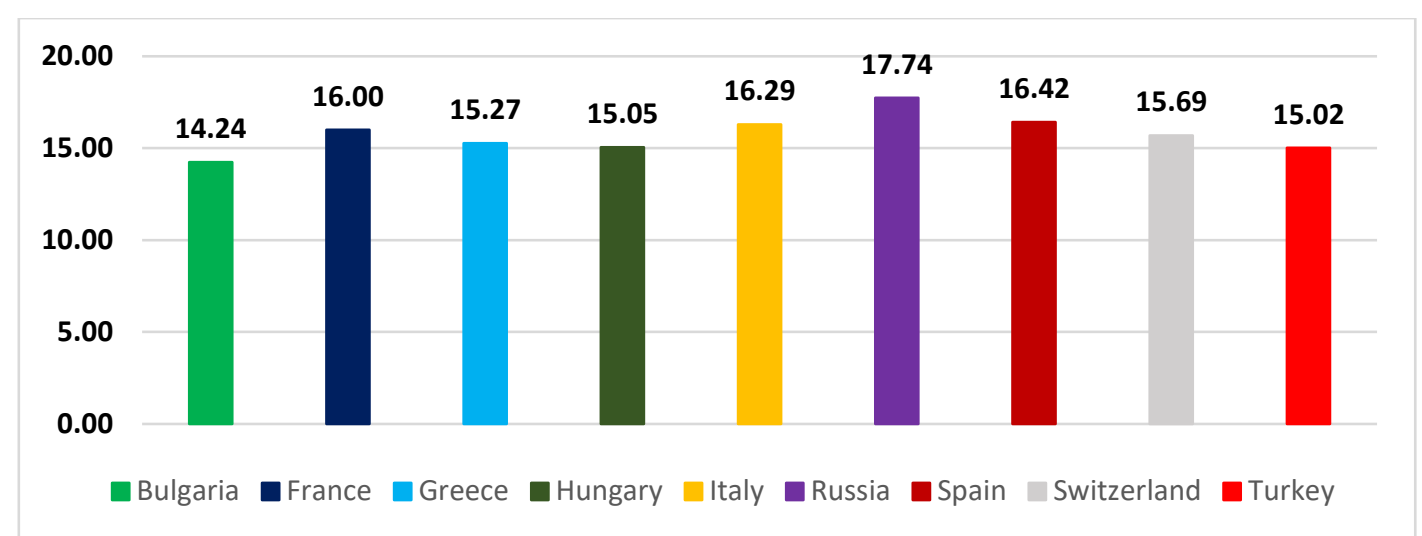

Figure 3.1: Ariana point averages of the countries that participated continuously in 2014-2019

Ariana point averages and total average and standard deviation values of 9 countries participating continuously in 2014-2019 are given in table 3.3. In all the years examined, it was seen that Russia received the highest athlete points. It has been understood that Spain, Italy, France and Switzerland are in the top 5 among nine countries.

Table 3.3: Ariana point averages of the countries participating for 6 consecutive years

\begin{tabular}{|l|c|c|c|c|c|c|c|}
\hline & $\mathbf{2 0 1 4}$ & $\mathbf{2 0 1 5}$ & $\mathbf{2 0 1 6}$ & $\mathbf{2 0 1 7}$ & $\mathbf{2 0 1 8}$ & $\mathbf{2 0 1 9}$ & $\begin{array}{c}\text { Total Mean and } \\
\text { Standard. D. }\end{array}$ \\
\hline Bulgaria & 14.9336 & 14.8984 & 15.2350 & 13.7720 & 14.2954 & 13.6070 & $14.2448 \pm 0.93$ \\
\hline France & 16.1333 & 16.1993 & 15.6979 & 15.3523 & 16.4863 & 16.5733 & $16.0024 \pm 1.04$ \\
\hline Greece & 15.8107 & 15.8437 & 15.4400 & 14.2047 & 15.6521 & 14.6621 & $15.2665 \pm 0.97$ \\
\hline Hungary & 15.8253 & 15.1837 & 13.8632 & 14.2633 & 15.8263 & 14.1350 & $15.0536 \pm 1.10$ \\
\hline Italy & 16.8630 & 16.4193 & 15.9088 & 15.2460 & 16.8758 & 16.3900 & $16.2853 \pm 0.88$ \\
\hline Russia & 17.9209 & 17.6960 & 17.8521 & 17.2333 & 18.3242 & 17.5617 & $17.7383 \pm 0.53$ \\
\hline Spain & 16.6012 & 16.4468 & 15.9610 & 15.8840 & 17.0225 & 16.4700 & $16.4186 \pm 0.89$ \\
\hline Switzerland & 15.7630 & 15.9683 & 15.5558 & 15.3047 & 16.1750 & 15.4000 & $15.6877 \pm 0.96$ \\
\hline Turkey & 15.0172 & 15.2845 & 15.1296 & 14.4027 & 15.6704 & 14.6650 & $15.0184 \pm 0.93$ \\
\hline
\end{tabular}

Ariana's figure points of the same athletes at different ages were compared. For this, the points are divided into groups of athletes aged 13-14, 14-15 and 13-15. Since the groups did not show normal distribution, the Wilcoxon Signed Ranks test, which is one of the 
non-parametric tests, was applied (Table 3.4). Ariana points of the same athletes 13 years and 14 years, 14 years and 15 years, and 13 years and 15 years old were compared. Accordingly, the points of 81 athletes in the 13 and 14 age groups, 210 athletes in the 14 and 15 age groups and 52 athletes in the 13 and 15 age groups were compared. When the Ariana figure points of the same athletes were divided into 13-14, 14-15 and 13-15 age groups, it was understood that there were significant differences between the groups $(\mathrm{p}<0.01)$.

Table 3.4: Ariana points comparison of the same athletes aged 13-14, 14-15 and 13-15

\begin{tabular}{|c|c|c|c|c|c|c|}
\hline Age groups & & $\mathbf{n}$ & Mean Rank & Sum of Ranks & $\mathrm{Z}$ & p \\
\hline \multirow{3}{*}{13 and 14 ages } & Negative ranks & 22 & 27.34 & 601.50 & \multirow{3}{*}{-4.570} & \multirow{3}{*}{$0.000^{*}$} \\
\hline & Positive ranks & 55 & 43.66 & 2401.50 & & \\
\hline & Ties & 4 & & & & \\
\hline \multirow{3}{*}{14 and 15 ages } & Negative ranks & 83 & 89.64 & 7440.00 & \multirow{3}{*}{-3.666} & \multirow{3}{*}{$0.000^{*}$} \\
\hline & Positive ranks & 122 & 112.09 & 13675.00 & & \\
\hline & Ties & 5 & & & & \\
\hline \multirow{3}{*}{13 and 15 ages } & Negative ranks & 17 & 15.56 & 264.50 & \multirow{3}{*}{-3.866} & \multirow{3}{*}{$0.000^{*}$} \\
\hline & Positive ranks & 35 & 31.81 & 1113.50 & & \\
\hline & Ties & 0 & & & & \\
\hline
\end{tabular}

${ }^{*} \mathrm{p}<0.01$

The figure of Ariana is the basis for some junior and senior elements. Table 3.5 shows the elements formed by the movements containing the Ariana figures.

Table 3.5: The relationship of Ariana figure transition movements with the elements

\begin{tabular}{|l|l|}
\hline Parts of the Ariana figure & \multicolumn{1}{c|}{ Element descriptions } \\
\hline Walkover Back & Senior 2nd solo element: The beginning part \\
\hline Walkout Front & $\begin{array}{l}\text { - Senior 3rd solo element: } \text { End of middle part } \\
\text { - Senior 4th duet element: End of middle part }\end{array}$ \\
\hline - Senior 3rd team element: End of middle part \\
\hline
\end{tabular}




\section{Discussion}

In artistic swimming, many studies have been carried out to determine the physiological responses of athletes aged 13-15 years, junior and senior age groups. It is stated that the majority of the studies involved female athletes. In the studies, the measurement results of the athletes during the competition and in laboratory tests were examined (Ponciano et al., 2018). Some such research includes figure swimming figures. Studies such as the application and technical examination of the analysis of the specified figure were carried out. In this context, the figure of Ariana, which we examined in our research, has the characteristics of competition points, competition performance, and figure analysis.

Studies are carried out to improve the technical skills and levels of athletes aged 13-15. It was determined that there was an improvement in the performance levels with the visual training program applied to the artistic swimming athletes under the age of 15. It has been stated that there is a statistical correlation between the development of the visual skills of the athletes and the artistic swimming performance levels (Fouad Ahmed and Taher Shosha, 2010). In order for the athletes of this age group to reach a successful level, researches are conducted on various training practices. In our research, Ariana's artistic swimming figure, which will contribute to the development of the athlete's performance technically, has been examined and the movements that this figure forms the basis of are determined. Technical elements were evaluated through video analysis to verify the reliability of the artistic swimming competition scoring. The results of the study show that a video is a reliable tool for training artistic swimming judges (Ponciano et al., 2018).

In various researches, some figures and elements were analyzed. Rio, Porpoise Continuous Spin $720^{\circ}$, Aurora Twirl, Whirlwind and Vertical Twist Spin figures were also examined in the study on the evaluation of artistic swimming performances of athletes (Ntomali et al., 2021). An analysis was made on the Thrust movement, which forms the basis of the Barracuda figures in artistic swimming. It has been stated that the examination of underwater footage of movements with video analysis is effective in applying the right technique. Thanks to the study, it is stated that it is possible to improve the figure evaluation results (Joseph et al., 2008). The figures of Ballerina, Neptunus and Porpoise involved in artistic swimming were analyzed. The figures were examined with underwater video shoots and studied on the body kinematics of the athletes (Ong et al., 2010). Explosive power in athletes was studied with Boost and Barracuda movements. It is recommended to use some artistic swimming movements and figures to determine sport-specific power capacities (Peric et al., 2012). In our study on Ariana figure points, the distribution between countries was determined by years by determining the athlete levels. In the 13-15 group, which is the youngest age at the national team level, the athlete levels of the countries were taken into account. In order to achieve successful results in competitions, it is important to compare country figure points levels.

Studies on artistic swimming figures generally include studies to improve athlete performance (Joseph et al., 2008; Ong et al., 2010). It is important to compare the competition points in detail with video analysis. By following the figure point 
development of the same athletes over the years, it contributes to the development of competition performance. A study was conducted on the performances of athletes in artistic swimming COMEN Cup competitions in 2017 and 2018. Ariana's figure points in the competitions were found to show an $8.9 \%$ improvement in the performance of the athletes who competed in both years. It has been understood that there is a similarity between the 2017 COMEN Cup competition points, which is the end of the four-year figure period of artistic swimming, and 2018, the first of the other four-year figure period (Akgün, 2020).

Studies have been conducted to examine the cardiorespiratory and metabolic responses of the 13-15 age group in artistic swimming. It has been understood that the aerobic exercise capacity and special anaerobic exercise capacity of artistic swimmers at this age develop rapidly (Bante et al., 2007; Chen et al., 2010). In most studies on artistic swimming, it was seen that elite and national team level athletes of different age groups were examined (Bante et al., 2007; Dimitrova, 2015). A pressure distribution measurement method was used to estimate the non-constant fluid forces acting on the hand during sculling movements performed by elite artistic swimmers. Because sculling movements produce vertical thrust, they help athletes stay in a stable position in the water. As a result of the study, it was understood that the athletes needed advanced sculling movement techniques (Homma et al., 2019). Since movement transitions are important in all competitions of artistic swimming, it has been stated that it is beneficial to study those with high difficulty levels in training programs. Figure studies should be carefully prepared in training plans for athlete development and preparation for competitions. For the successful technical development of athletes, professional training practices should be supported by analyzing them with scientific methods. Understanding and examining artistic swimming figures and movement transitions are one of the factors that significantly increase the development of athletes (Akgün, 2020).

\section{Conclusion}

As a result of our research, it has been understood that the figure point averages may vary depending on the number of countries and athletes participating in artistic swimming COMEN Cup competitions. As the age of the athletes' increases, the increase in the Ariana figure point differs significantly. This situation is also seen in the points of the same athletes in different age groups. The points of Bulgaria, France, Greece, Hungary, Italy, Russia, Spain, Switzerland and Turkey, which participated uninterruptedly in the years covering the research, are decisive in terms of estimating the competition ranking and Ariana figure points. It is important to consider the country point levels determined for the competition ranking and athlete development.

As a result of the analysis, the similarity and difference status of the Ariana figure points of the athletes were determined. The average point according to the year of the competition and the average point of the countries that regularly participate have been made suitable for planning for the development of athletes. With the study we prepared, 
it was possible to make figure point plans in determining the performance development goals of artistic swimmers.

\section{Conflict of Interest}

There are no potential conflicts of interest on this article.

\section{About the Author}

Gökçe Akgün, PhD student, Department of Movement and Training Sciences, Institute of Graduate Studies, İstanbul University - Cerrahpaşa, Turkey.

\section{References}

Akgün, G. (2020). Artistik yüzmede yaygın olarak kullanılan figür ve hareket geçişlerinin analizi. Özgür Karataş (Ed.). Spor Bilimleri Alanında Akademik Çalışmalar-2 Cilt 2, Gece Kitaplığı, Ankara, Turkey, pp. 145-156.

Akgün, G. (2020). Dört yıllık süreyle güncellenen artistik yüzme figürlerinin 13-15 yaş kız sporcuların yarışma puanlarına göre analizi. III. International congress of physical education, sport, recreation and dance, Online presentation, İstanbul.

Bante, S., Bogdanis, G. C., Chairopoulou, C. \& Maridaki, M. (2007). Cardiorespiratory and metabolic responses to a simulated synchronized swimming routine in senior and comen national level athletes. Journal of Sports Medicine and Physical Fitness, 47(3), 291-299.

Chen, A. Cai, G., Shen, X., Xu, W., Liu, Y., Qiao, G. \& Li, J. (2010). Characteristics of physical capacities of synchronized swimmers at the age of 7 15 in China. Journal of Physical Education, 17(12), 96-100.

COMEN.

(2008).

Comen

Statute.

https://www.finsicilia.it/comen2010/documenti/statutoComen.pdf. Accessed 2 July 2021.

COMEN. (2010). Confederation Mediterraneenne de Natation. https://koe.org.gr/uploads/docs/kolymvisi/MedSynSwCupaddress.pdf. Accessed 2 July 2021.

Dimitrova, B. (2015). Comparative analysis for the hypoxic sustainability of the synchronized swimmers from Bulgaria, Greece and Turkey. Research in Kinesiology, 43(2), 180-184.

Fédération Internationale de Natation (2013). 2013 - 2017 FINA Synchronized Swimming Manual for Judges, Coaches \& Referees. www.fina.org.

Fédération Internationale de Natation (FINA). (2017). Final Report of The FINA Ad Hoc Committee on Artistic Swimming Degrees of Difficulty. www.fina.org.

Fédération Internationale de Natation (FINA). (2018). FINA artistic swimming manual for judges, coaches \& referees 2017 - 2021. www.fina.org.

Fouad Ahmed, M. \& Taher Shosha, N. (2010). Efficiency of the program of visual training. Procedia Social and Behavioral Sciences, 5, 2082-2088. 
Homma, M. Okamoto, Y. \& Takagi, H. (2019). How do elite artistic swimmers generate fluid forces by hand during sculling motions? Sports Biomechanics, 1-15.

Joseph, S., Meng, M. C. \& Wilson, B. D. (2008). Descriptive analysis of thrust in synchronized swimming. ISN Bulletin, 1(2), 41-50.

Ntomali, S., Adamakis, M., Venetsanou, F., Chairopoulou, C. \& Psychountaki, M. (2021). Which factors are influencing artistic swimming performance? European Journal of Physical Education and Sport Science, 6(12), 62-76.

Ong, P. M. B., Mascardo, E. D. \& Pobre, R. F. (2010). Feature extraction of a synchronized swimmer from underwater videos. The Manila Journal of Science, 6(1), 39-46.

Peric, M., Zenic, N., Mandic, G. F., Sekulic, D. \& Sajber, D. (2012). The reliability, validity and applicability of two sport-specific power tests in synchronized swimming. Journal of Human Kinetics, 32, 135-145.

Ponciano, K. R., Fugita, M., Figueira, A. J., Silva, C. B. D., Meira, C. D. M. \& Bocalini, D. S. (2018). Reliability of judge's evaluation of the synchronized swimming technical elements by video. Revista Brasileira de Medicina do Esporte, 24, 182-185.

Ponciano, K., Miranda, M. L. D. J., Homma, M., Miranda, J. M. Q., Figueira Junior, A. J., Meira Junior, C. D. M. \& Bocalini, D. S. (2018). Physiological responses during the practice of synchronized swimming: a systematic review. Clinical Physiology and Functional Imaging, 38(2), 163-175.

The Ligue Européenne de Natation (2019). European Championships in Artistic (Synchronised) Swimming. http://www.len.eu.

The Ligue Européenne de Natation (2020). European Championships Swimming (50m), Diving, Artistic Swimming and Open Water Swimming. http://www.len.eu. 
Gökçe Akgün

COMEN CUP COMPETITION POINTS ANALYSIS OF ARIANA FIGURE IN ARTISTIC SWIMMING

Creative Commons licensing terms

Authors will retain the copyright of their published articles agreeing that a Creative Commons Attribution 4.0 International License (CC BY 4.0) terms will be applied to their work. Under the terms of this license, no permission is required from the author(s) or publisher for members of the community to copy, distribute, transmit or adapt the article content, providing a proper, prominent and unambiguous attribution to the authors in a manner that makes clear that the materials are being reused under permission of a Creative Commons License. Views, opinions and conclusions expressed in this research article are views, opinions and conclusions of the author(s). Open Access Publishing Group and European Journal of Physical Education and Sport Science shall not be responsible or answerable for any loss, damage or liability caused in relation to/arising out of conflict of interests, copyright violations and inappropriate or inaccurate use of any kind content related or integrated on the research work. All the published works are meeting the Open Access Publishing requirements and can be freely accessed, shared, modified, distributed and used in educational, commercial and non-commercial purposes under a Creative Commons attribution 4.0 International License (CC BY 4.0). 